\title{
Long-term lifestyle change reduces several risk factors for type 2 diabetes mellitus in Brazilian subjects with impaired glucose tolerance
}

\author{
K. C. P. McLellan ${ }^{1}$, M. C. de Souza ${ }^{2}$ and A. C. Lerario ${ }^{3}$ \\ ${ }^{1}$ School of Nutrition, Pontificia Catholic University, Campinas, SP/Brazil, ${ }^{2}$ Nutrition Course, Faculty Heath Sciences \\ Methodist University of Piracicaba, SP/Brazil and ${ }^{3}$ Medical School, University of Sao Paulo, SP/Brazil
}

Lifestyle is directly related to the incidence of type 2 diabetes (DM2), a risk dramatically elevated by obesity and inactivity ${ }^{(1)}$. This study reports the effects of a 12-month nutritional education and lifestyle intervention program in a Brazilian urban community, on metabolic improvement, body composition and eating behaviour. A total of 2043 individuals were screened for capillary glucose levels and among them 142 people presented fasting plasma glucose above $100 \mathrm{mg} / \mathrm{dl}$ and also two risk factors for developing DM2 and CVD. A total of sixty seven subjects aged from 30 to 85 years were included in the study and were divided in two groups: compared group ( $n$ 43) and intervention ( $n$ 24) group (CG and IG, respectively). Availability to attend the group session was considered for including individuals in the IG. All individuals in both groups had their clinical, metabolic and dietetic profiles examined. The subjects in the IG were given detailed advice about diet, exercise and lifestyle modification through monthly individual visits and group meetings every 2 weeks for 12 months. An individual visit was offered to the GC at the beginning of the study and after 12 months. A paired $t$-test was used to examine differences in the outcomes between baseline and 12 months.

Baseline characteristics of the participants are given in the table below. The IG patients achieved a weight loss of 5.10\% $(P<0.001)$ while the CG had an increase of $0.54 \%$ from their initial weight. IG patients reduced $3.3 \%(P<0.05)$ and $6.8 \%(P<0.01)$ of their waist circumference (WC) and body fat $\%$, respectively. Fasting and postprandial glucose levels were reduced $13.5 \%(P<0.05)$ and $20.9 \%$ $(P<0.05)$, respectively, in the IG. The assessment of dietary composition at the beginning and at the end of the study showed that cholesterol and caloric intake significantly decreased inside the IG patients ( $49.5 \%$ and $4.7 \%$, respectively).

\begin{tabular}{|c|c|c|c|c|c|c|c|c|c|c|}
\hline & \multicolumn{5}{|c|}{ IG } & \multicolumn{5}{|c|}{$\mathrm{CG}$} \\
\hline & \multicolumn{2}{|c|}{ Baseline } & \multicolumn{2}{|c|}{12 months } & \multirow[b]{2}{*}{$P$ value } & \multicolumn{2}{|c|}{ Baseline } & \multicolumn{2}{|c|}{12 months } & \multirow[b]{2}{*}{$P$ value } \\
\hline & Value & SD & Value & $\mathrm{SD}$ & & Value & SD & Value & SD & \\
\hline Weight (kg) & 67.61 & 14.8 & 64.18 & 13.5 & $<0.001$ & 75.78 & 15.2 & 76.20 & 16.3 & 0.43 \\
\hline BMI $\left(\mathrm{kg} / \mathrm{m}^{2}\right)$ & 26.59 & 5.3 & 25.00 & 4.5 & $<0.001$ & 28.46 & 4.5 & 28.60 & 5.2 & 0.98 \\
\hline $\mathrm{WC}(\mathrm{cm})$ & 88.53 & 10.6 & 85.57 & 9.9 & $<0.05$ & 91.19 & 17.0 & 92.50 & 18.1 & 0.34 \\
\hline Body fat (\%) & 33.36 & 9.61 & 31.10 & 9.51 & $<0.01$ & 35.98 & 7.4 & 36.21 & 8.03 & 0.88 \\
\hline Fasting plasma glucose $(\mathrm{mg} / \mathrm{dl})$ & 105.0 & 21.6 & 90.83 & 14.2 & $<0.05$ & 91.79 & 18.3 & 90.20 & 28.9 & 0.72 \\
\hline 2 -h plasma glucose $(\mathrm{mg} / \mathrm{dl})$ & 138.0 & 40.8 & 109.17 & 27.4 & $<0.05$ & 117.80 & 31.5 & 109.57 & 38.9 & 0.36 \\
\hline Serum total cholesterol $(\mathrm{mg} / \mathrm{dl})$ & 213.42 & 85.5 & 164.50 & 49.9 & $<0.05$ & 170.43 & 62.7 & 163.73 & 45.1 & 0.60 \\
\hline Energy $(\mathrm{kJ})$ & 6982.05 & 2580.27 & 6650.76 & 1210.43 & $<0.05$ & 6046.55 & 2873.15 & 7471.58 & 2311.66 & 0.04 \\
\hline Carbohydrates (g) & 241.47 & 91.3 & 214.20 & 41.0 & 0.29 & 191.25 & 25.0 & 260.87 & 69.9 & 0.07 \\
\hline Proteins $(\mathrm{g})$ & 85.54 & 37.7 & 68.87 & 12.8 & 0.14 & 65.67 & 34.0 & 74.41 & 30.5 & 0.40 \\
\hline Lipids (g) & 54.43 & 18.4 & 48.90 & 14.0 & 0.20 & 40.52 & 23.1 & 53.83 & 30.6 & 0.10 \\
\hline SFA $(g)$ & 18.32 & 10.2 & 8.51 & 1.4 & 0.18 & 9.91 & 6.5 & 10.98 & 8.3 & 0.71 \\
\hline Cholesterol (mg) & 183.69 & 55.4 & 92.72 & 44.7 & $<0.001$ & 155.01 & 81.0 & 118.25 & 81.7 & 0.15 \\
\hline Fibres (g) & 12.23 & 5.7 & 12.13 & 5.5 & 0.94 & 7.72 & 10.7 & 7.93 & 7.8 & 0.93 \\
\hline
\end{tabular}

IG, Intervention group; CG, Compared group; values in mean; SD, standard deviation.

Lifestyle modification program can reduce known risk factors for DM2 and CVD in a Brazilian urban community. This suggests that carrying out primary prevention of DM2 and CVD through lifestyle education, especially by emphasising nutrition and physical activity, is very important in terms of public health and should be part of the routine of Health Care System.

1. Lindstrom J, Louheranta A, Mannelin M et al. (2003) The Finnish Diabetes Prevention Study (DPS): lifestyle intervention and 3-year result on diet and physical activity. Diabetes Care 26, 3230-3236. 